\title{
Overview of the frontal sinus anteroposterior size using lateral cephalometric radiographs and chronological age as forensic identification
}

\author{
Georgiana Marsya*, Fahmi Oscandar*, Inne Suherna Sasmita** \\ *Department of Dentomaxillofacial Radiology, Faculty of Dentistry, Universitas Padjadjaran, \\ Indonesia \\ **Department of Pedodontics Dentistry, Faculty of Dentistry Universitas Padjadjaran, Indonesia
}

\begin{abstract}
Introduction: One part of the most important individual identification procedure is approximate age can be done on an individual living or dead. Judging from some of the methods that have been there, have not found a method forecasts age through the frontal sinuses, particularly research conducted in Indonesia. The frontal sinus can be used for identification because the frontal sinuses began to evolve and look at radiographs at the age of 7 years and did not change after the age of 20 years, it reveals the existence of differences in the size of the frontal sinuses with age. Objective: To asses of the frontal sinus anteroposterior size based on against lateral cephalometric radiographs chronological age as forensic identification. Methods: A number of samples are 502 lateral cephalometric patient data from secondary data of patients aged 7-20 years, 335 pieces of lateral cephalometric. Purpose of of the study was to asses the frontal sinus anteroposterior size chronological age as forensic identification. Radiograph female patients and 167 pieces in male patients. Data anteroposterior size of the frontal sinus is obtained by pulling the longest line perpendicular to the line of Sh-Sl. Results: The results showed that at the age of 7 years the average size of the frontal sinus anteroposterior $4.20 \mathrm{~mm}$ and $5.05 \mathrm{~mm}$ which is the smallest size, while the average size of the biggest, by $8.46 \mathrm{~mm}$ in women and men at the age of 11.37 $\mathrm{mm} 20$ years. Conclusions: In women, the fastest increase occurred at the age of 7-8 years, males at the age of 16-18 years. The frontal sinuses anteroposterior size increases with age, both men and women.
\end{abstract}

Keywords: Frontal sinuses, Age chronologies, Forensic Identification.

P-ISSN 1979-0201, e-ISSN 2549-6212 Available from:http://jurnal.unpad.ac.id/pjd/index

DOI:http://dx.doi.org/10.24198/pjd.vol29no2.13631

Submission: May 2017 Publishing: July 2017

Corresponding author: Inne Suherna Sasmita, Department of Pedodontic Jl. Sekeloa Selatan I, Bandung, Indonesia Email: innesuhernasasmita@yahoo.co.id or inne.sasmita@fkg.unpad.ac.id 


\section{INTRODUCTION}

The frontal sinus, as one of the paranasal sinuses, lies posterior to frontal bone superciliary sinuses. This sinus can be detected in children as early as 7 years old and remain until it reach the age of $20 .^{1}$ Along with craniofacial growth, the frontal sinuses swell to fill the space created by craniofacial growth. Sinus growth not as a function of structural adaptation process of facial growth were to maintain contact with the nasal bone and maxilla. ${ }^{2}$ Sinus enlargement process is more likely influenced by physiological processes rather than external factors such as orthodontic treatment. The growth of the frontal sinuses can be measured easily and objectively based on the depth by mean of Erturk technique. Previous studies which using lateral cephalometric radiographs revealed that the growth of the frontal sinus is alongside with the growth in height, which increases with age. ${ }^{2}$

The development of the frontal sinuses may be used as forensic identification in determining the age, namely with the anthropological method ${ }^{3}$ There are three main elements in anthropology examination procedures, which incorporate the determination of race, gender, and age at death. Identifying a person's age is considered difficult, yet it plays an important part in any identification procedurs where lack of information related to victim could be obtained. ${ }^{4}$

The most effective tool to collect information in an anthropological methods for identifying victim's skeletal identification is remain the radiographic analysis. ${ }^{5}$ Some other tools are histological and biochemical methods. Various radiology method has certain advantages compared to the other two methods, where it considered more simple, fast, low cost, and nonmutilating. Furthermore, it can be applied to identify the age of both the people who have died or who are still alive. ${ }^{3}$

Radiograph type that can be used to examine frontal sinus in anteroposterior direction is the lateral cephalometric radiograph. Lateral cephalometric radiograph is an extra oral radiography that is commonly used in orthodontic treatment to assess the teeth relation of the jaws, and determining the jaw bone relation to the whole facial aspect. ${ }^{6}$
Most of the victims are often found incomplete and decayed. These conditions are unfavourable for a lateral cephalometric radiograph to be taken, as it can only be applied when the victim is in an upright position. A conventional true lateral cephalometri technique can be obtained by releasing an intraoral X-Ray tube from its frame, so that the radiation will spread out wider to capture the image of the frontal sinus. ${ }^{7}$ This radiographic technique can facilitate the forensic team in identifying, without the need to perform an autopsy to remove the tissue that covers the frontal sinuses.

\section{METHODS}

The research is a descriptive study, non experiment. The research materials were a digital lateral cephalometric radiographs archive of patients aged 7-20 years in Radiology Department of Dental Hospital Universitas Padjadjaran, Bandung. The sampling procedure using a total sampling. The samples were 502 lateral cephalometric radiographs of patients aged 7-20 years; 335 female patients and 167 male patients.

The exclusion criteria of sample is radiographs were taken from December 2009 until November 2014 which has been destroyed. The inclusion criteria for the sample were radiographs

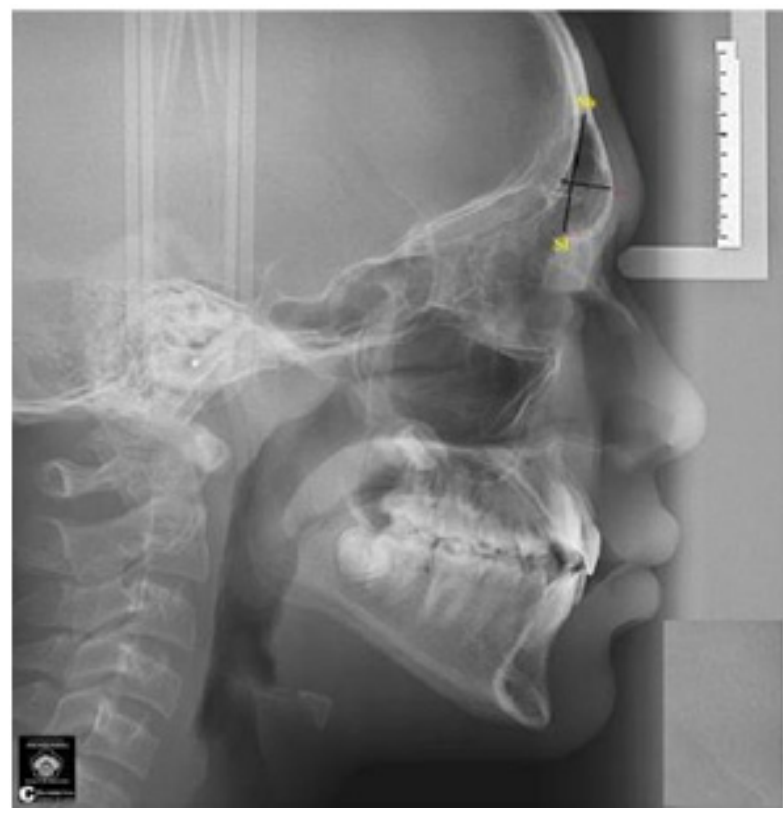

Figure 1. Measurement of the frontal sinus anteroposterior the method according to Erturk ${ }^{3}$ 
which were taken from December 2009 until November 2014 with feature of the sinus clearly visible. The size of the frontal sinus was measured using Erturk method as shown in Figure 1.

Highest point (Sh) and the lowest poin (Sl) of the sinuses were pinpointed by drawing lines between these two points ( $\mathrm{Sh}$ to $\mathrm{Sl}$ ), the anteroposterior size of the frontal sinus can be determined by taking a line perpendicular to Sh-Sl on the outermost of the frontal bone. Measurements of the data collected were than

Table 1. Average size of the frontal sinus anteroposterior in female

\begin{tabular}{cccc}
\hline No. & $\begin{array}{c}\text { Age } \\
\text { (vear) }\end{array}$ & Mean $(\mathrm{mm})$ & $\begin{array}{c}\text { Standard } \\
\text { Deviation }\end{array}$ \\
\hline 1 & 7 & 4.20 & 0.70 \\
2 & 8 & 5.06 & 0.97 \\
3 & 9 & 5.81 & 0.46 \\
4 & 10 & 6.26 & 0.65 \\
5 & 11 & 6.71 & 1.03 \\
6 & 12 & 6.72 & 0.71 \\
7 & 13 & 6.66 & 1.54 \\
8 & 14 & 7.49 & 1.52 \\
9 & 15 & 7.59 & 2.33 \\
10 & 16 & 7.73 & 1.08 \\
11 & 17 & 7.68 & 1.52 \\
12 & 18 & 7.95 & 1.12 \\
13 & 19 & 8.21 & 1.40 \\
14 & 20 & 8.46 & 1.81 \\
\hline
\end{tabular}

Table 2. Average size anteroposterior frontal sinus in male

\begin{tabular}{cccc}
\hline No. & $\begin{array}{c}\text { Age } \\
\text { (year) }\end{array}$ & Mean $(\mathrm{mm})$ & $\begin{array}{c}\text { Standard } \\
\text { Deviation }\end{array}$ \\
\hline 1 & 7 & 5.05 & 0.57 \\
2 & 8 & 6.00 & 0.34 \\
3 & 9 & 6.21 & 0.51 \\
4 & 10 & 7.06 & 1.16 \\
5 & 11 & 7.16 & 1.26 \\
6 & 12 & 7.54 & 0.80 \\
7 & 13 & 7.77 & 0.89 \\
8 & 14 & 8.15 & 2.27 \\
9 & 15 & 8.43 & 1.89 \\
10 & 16 & 8.51 & 1.09 \\
11 & 17 & 9.58 & 1.20 \\
12 & 18 & 11.03 & 4.35 \\
13 & 19 & 11.22 & 1.96 \\
14 & 20 & 11.36 & 2.22 \\
\hline
\end{tabular}

statistically analized for the average size and its standard deviation.

\section{RESULTS}

The average size of the anteroposterior in every age differs between male and female, where male are bigger than female (Table 1 and 2). The reason for choosing the sample in the age of 7-20 years with the understanding that at the age of 7 years, frontal sinuses began to be observed on radiographs, while in 20 years it will reached its maximum development. In Table 1 and Table 2, the anteroposterior size of the frontal sinus in males and females showed an increase with age.

\section{DISCUSSION}

The frontal sinus grows incorporation with the growth of the craniofacial. Sinus enlargement process is influenced by physiological processes. The frontal sinus enlarges and fills the space for the growth of the craniofacial sinuses as part of the structural adaptation process to the forward and lower facial growths. the growth of the middle and front direction of the external frontal bone occurs in order to stay in contact with the nasal and maxillary bonesThe frontal sinus experienced the biggest growth toward anteroposterior ${ }^{2}$.

Refering to Table 1 and 2 , the anteroposterior size of the frontal sinus correspond to age. This result supports the previous study This is according to research conducted by Wijaya and Hdayat $^{1}$ which stated that the growth of the frontal sinus is incorporate with the growth in height, which increases by age. In addition, the anteroposterior frontal sinus size is proportional to age, sinus development starts from 7-20 years of age, with an average age of 13 and 17 years and varies.

It is known from table 1 that the development of anteroposterior measures in women varies with age. the fastest development in women aged 7-8 years, this is in line with research by Duque and Casiano which states that the development of the frontal sinuses continues not only in the intrauterine but also in the immediate postnatal period expanded significantly during the onset of puberty, this corresponds to the average age of puberty in women is between 8-13 years. ${ }^{9,10}$ 
The average size of the frontal sinus anteroposterior in women and men

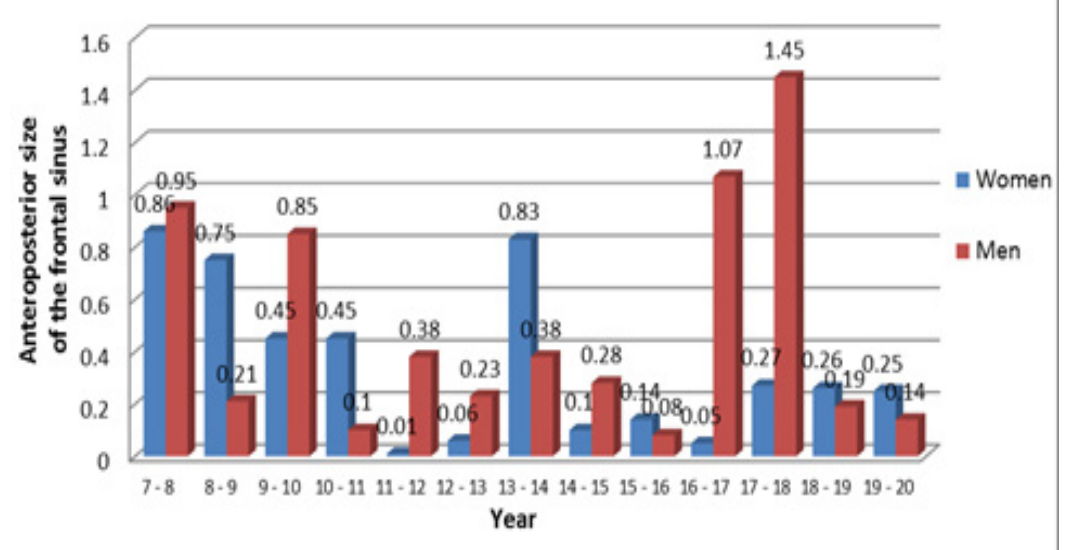

Figure 2. The average size of the frontal sinus anteroposterior in women and men

Table 2 shows the progression of anteroposterior sinus size in males and the fastest development occurring at the age of 16-18 years. It is also in accordance with Duque and Casiano too, ${ }^{7}$ and the puberty in males begins at the age of $15-16$ years. ${ }^{10}$ The largest development of anteroposterior size of the average frontal sinuses occurs at the age of 20 years, at a time when growth and development reaches the maximum. ${ }^{2}$

There are also differences in the average of the frontal sinus anteroposterior size between men and women, average size sinus in males is greater than in women. The results were similar to the study conducted by Hidayat Wijaya in 2009 , that the average size of the anteroposterior frontal sinus in males of $11.07 \mathrm{~mm}$, whereas in this study was $11.37 \mathrm{~mm}$, and the average size in women by $9.88 \mathrm{~mm}$, whereas in this study by 8.46 $\mathrm{mm}^{2}$

The research conducted by Lusted showed clearly that the fastest growth rate was in the age of 13-18 years, which increased by $6 \mathrm{~mm} .{ }^{11}$ This difference may be due to the greater number of samples used by Lusted. Such differences can also due to racial differences in the research subject, as has been known Lusted took samples from London and the most of whom were Caucasian, while in this study using majority Malay mongoloid race. Caucasians have a larger body posture that it can affect to the anteroposterior size of the frontal sinus. ${ }^{11}$ Differences can also be caused by different methods and types of radiographs used. Lusted studied using Caldwell Projection whereas in this study using lateral cephalometric radiograph with the Erturk method. ${ }^{11}$

\section{CONCLUSIONS}

In women, the fastest increase occurred at the age of 7-8 years, while in males at the age of 16 . 18 years. The frontal sinuses anteroposterior size increases by age, and by gender.

\section{ACKNOWLEDGMENTS}

The authors declare no potential conflicts of interest with respect to the authorship and/or publication of this article.

\section{REFERENCES}

1. Moore KL. Clinically oriented anatomy. $5^{\text {th }} \mathrm{ed}$. USA: Lippincott: Williams \& Wilkins, 2006.

2. Wijaya $\mathrm{H}$ et al. The relationship between the depth of the frontal sinus and bone maturation hand. Dentika Dental 2009;14(2);103-8.

3. Panchbhai AS. 2011. Dental radiographic indicators, a key to age estimation. Dentomaxillofacial Radiology Journal. 4:199-212. Available from: http://www.ncbi. nlm.nih.gov/pmc/articles/PMC3520308/. (accessed 25 July 2015).2011

4. Vodanović M, Dumančić J, Galić I, Pavičin $S$, Petrovečki $M$, Cameriere $R$, et al. Age estimation in archaeological skeletal remains: evaluation of four non-destructive age calculation methods. 2011. Available at: http: / / www.iofos. eu/ Journals / JFOS\%2520 Dec11/3_AGE\%2520ESTIMATION.pdf (accessed 22 June 2015) 
5. Patil N, Karjodkar FR. Uniqueness of radiographic patterns of the frontal sinus for personal identification. PMC 2012;3.

6. Whaites E. Essentials of dental radiography and radiology. $3^{\text {rd }}$ ed. London: Churchill Livingstone; 2003.

7. White SC, Pharoah PJ. Oral radiology. $6^{\text {th }}$ ed. St. Louis: Elsevier; 2009.
8. Sastroasmoro S. Basic-basic clinical research methodology. $2^{\text {nd }}$ ed. Jakarta: Sagung Seto; 2002.

9. Duque CS, Casiano RR. Surgical anatomy and embryology of the frontal sinus. Berlin: Springer Heidelberg 2005;21-31.

10. Biben A. Identifying Future kids puberty. Bandung: Mind; 2011. 